\title{
ENTREVISTA COM ROSÂNGELA GAVIOLI PRIETO
}

\author{
Edna Martins \\ Erica Aprecida Garrutti de Lourenço \\ Maria de Fátima Carvalho \\ Universidade Federal de São Paulo
}

Rosângela Gavioli Prieto é doutora em Educação, pela Universidade de São Paulo (2000), tendo expressiva atuação nessa área. Ao longo das duas últimas décadas, seu trabalho envolve estudo e discussão da política de educação especial brasileira, com destaque para os desdobramentos e formas por esta assumidas no âmbito do estado de São Paulo, com fins de análise de suas implicações sobre os modos de efetivação dessa modalidade de ensino, de seus efeitos sobre a organização da escola, sobre os estudantes com deficiência, transtornos globais do desenvolvimento e altas habilidades/superdotação e profissionais da educação nela envolvidos. Suas pesquisas e publicações mais recentes abordam, entre outros, os temas: inclusão escolar e exigências políticas, de gestão, administração e pedagógicas; construção das redes de apoio aos serviços pedagógicos especializados; especificidades dos serviços especializados de apoio pedagógico aos alunos público-alvo da educação especial; formação de professores para o atendimento de qualidade a esses alunos; avaliação na inclusão escolar etc.

Atualmente, é professora da Faculdade de Educação da Universidade de São Paulo, onde já foi chefe do Departamento de Administração Escolar e Economia da Educação (2009-2012) e, desde 2002, coordena o Grupo de pesquisa CNPq: Políticas de educação especial; coordenou a Linha temática de pesquisa do Programa de Pós-graduação da Feusp (2004-2013), em que continua na função de suplente; coordena o Grupo de Trabalho Educação Especial da Associação Nacional de Pós-graduação e Pesquisa em Educação Olh@res, Guarulhos, v. 3, n. 1, p. 219-236. Maio, 2015. 
(Anped).

Em entrevista concedida à Olh@res, a professora doutora Rosângela Gavioli Prieto expõe reflexões e questionamentos relacionados ao tema "diversidade, diferenças e inclusão na educação básica", destacando aspectos diversos da história e das atuais condições de efetivação de políticas e práticas de educação inclusiva. Ressalta os avanços frente à conquista do direito à educação para todos e os desafios a serem enfrentados nessa direção e, no cerne dessa discussão, destaca a importância da formação inicial e continuada de profissionais da educação.

Olh@res, Guarulhos, v. 3, n. 1, p. 219-236. Maio, 2015. 


\section{1) Começamos com uma pergunta que} nos permite situar nossa conversa frente ao tema desse dossiê da revista Olh@ res: diversidade, diferenças e inclusão na Educação Básica: quais as aproximações possíveis quando nos referimos à diversidade, diferenças e população alvo da educação especial e, por outro lado, quais as particularidades a serem ressaltadas quando pensamos em políticas públicas e na consideração das especificidades dessa população?

A primeira discussão que faço é a importância de cada vez mais buscarmos compreender quais conceitos atribuímos para diversidade, diferença e inclusão. É bastante difícil empreendermos uma discussão sem referências, porque se pode fazer uso desses conceitos - diversidade e diferença - pensando apenas em atributos visíveis, ou seja, atentando para características humanas manifestas no corpo, como tipo de cabelo, estatura, e naturalizar as diferenças humanas sem analisar como muitas características foram assumindo valores diferenciados na cultura, foram construídas historicamente hierarquias, para justificar e sustentar desigualdades. Por isso, precisamos Olh@res, Guarulhos, v. 3, n. 1, p. 219-236. Maio, 2015. buscar suas raízes históricas, as tendências tanto nos campos da ciência como na organização das relações sociais e das necessidades humanas. Fomos aprendendo a identificar, categorizar e classificar pessoas e, com isso, fomos criando maneiras de diferenciar normalidade de anormalidade e de usar essa divisão para justificar decisões de atendimento nos campos da educação, da saúde, por exemplo, de tal forma que hoje há lutas pela constituição de novos referenciais de atendimento. Na educação sente-se a necessidade de referenciais sobre ensino e aprendizagem que possam permitir a vasão de formas diversas de ser, estar, aprender e se expressar, com vistas a garantir que os alunos possam usufruir uma escola que se movimenta para identificar barreiras e promover condições de aprendizagem para todos.

Há também um discurso com certo teor de ingenuidade quando apenas ressalta o reconhecimento da diversidade como uma dimensão humana, sem contextualizá-la na sua relação com desigualdade. $\mathrm{O}$ uso que se pode fazer do termo diversidade nos permite pensar em acolhimento e respeito às diferenças, mas, ao nos voltarmos para as desigualdades 
econômicas, por exemplo, essa relação não se sustenta, pois significaria assumir que devemos acolher e respeitar a pobreza e é claro que não podemos conceber esse raciocínio, porque ele ajuda a manter o discurso da naturalização da desigualdade econômica que sustenta outras tantas formas de desigualdade.

Obviamente, em uma discussão mais alargada, ao compreender que os seres humanos têm o direito de ser e estar no mundo de maneiras diversas, encontramos respaldo para que discutamos, por exemplo, o respeito pelas pessoas com deficiência, no sentido de elas poderem se expressar, estar no mundo de maneiras a serem respeitadas pelo o que são, com todas as intervenções pedagógicas que requerem. Essa é uma maneira de compreendermos essas relações entre diversidade, diferença e a população-alvo da educação especial.

Nessa mesma pergunta, "por outro lado, quais as particularidades a serem ressaltadas quando pensamos em políticas públicas e na consideração da especificidade desta população?”, o grande risco desse discurso mais Olh@res, Guarulhos, v. 3, n. 1, p. 219-236. Maio, 2015. generalista é exatamente dizermos que somos todos iguais no plano dos direitos, temos que estar nas diferentes instituições - incluindo a escola e, ao estarmos na escola, deixamos de considerar as especificidades e, portanto, as intervenções específicas que podem se fazer necessárias para garantir o direito à aprendizagem. A relação entre igualdade e diferença é bastante complexa e deve ser pensada a partir da concepção de direitos e desigualdades. No caso de uma pessoa com deficiência, por exemplo, não considerar suas especificidades representa negligenciar um direito que já está na lei; ao desconsiderar a necessidade de intervenções específicas, contribui-se com a legitimação da ideia de que a matrícula na classe comum significa cumprimento do direito à educação e isto servir de justificativa para não promover condições necessárias à sua aprendizagem.

Vale lembrar que os direitos são construídos e conquistados; são consequência de lutas de grupos organizados ou de uma história de reivindicação. Ainda assim, não significa que eles automaticamente se transformam numa política pública. É necessário que 
se continue lutando, para que se saia do campo dos direitos, direitos positivados em lei, para o das ações do Estado para serem implantados.

2) Considerando sua experiência, engajamento e participação, nas últimas décadas, na discussão de questões relacionadas à educação especial e à inclusão escolar de alunos com deficiência - sobretudo em políticas públicas -, o que a Sra. aponta como avanços, conquistas desse campo?

Em um recorte mais atual, recorrendo especificamente à Constituição de 1988 , ao nos voltarmos para os direitos inseridos na Carta Magna, depois na LDB e outras normativas infraconstitucionais, estão assegurados o direito à educação e ao atendimento educacional especializado. Por serem as leis uma construção social, os direitos representam um determinado momento da história da sociedade, um determinado conjunto de forças. As leis carregam contradições, que na verdade refletem diferentes posições em relação, inclusive, aos direitos dessa população. Mais especificamente em relação à educação, temos aí no mínimo duas forças que, em alguns momentos, se opõem mais claramente e em outros não: a ideia de todos os alunos estudarem em classes comuns. E estas se expressam nos documentos normativos, quando nesses é mantida a possibilidade de os alunos público-alvo da educação especial serem atendidos fora da classe comum. Estamos em um momento favorável a conquistas de direitos. Os estados e municípios brasileiros estão com a tarefa de elaborar ou revisar e aprimorar seus planos de educação, o que pode resultar na garantia de inserção de objetivos e metas, visando à expansão dos direitos dessas pessoas e sua inclusão social e escolar.

3) Como, de seu ponto de vista, esses avanços têm impactado as práticas educacionais e a vida da população com deficiência?

Estamos em um momento da história em que já podemos considerar a presença de alguns resultados dessa política e também continuamos a fazer grandes apostas em um futuro mais promissor. De imediato, podemos dizer que temos um número maior de alunos nas escolas, se

Olh@res, Guarulhos, v. 3, n. 1, p. 219-236. Maio, 2015. 
compararmos com o que tínhamos há duas décadas e meia atrás. Constatamos também o acesso dos alunos com deficiência a níveis mais elevados de ensino, pois embora timidamente há uma porcentagem maior de ingressantes no ensino fundamental, que está alcançando as/os séries/anos finais desta etapa da educação básica e o ensino médio. Mas, não se pode deixar de registrar que ainda estamos longe de universalizar o acesso das pessoas com deficiência, desde a educação infantil ao nível superior de ensino, pois perdemos muitos que ingressam nesse processo. $\mathrm{O}$ investimento deve ser em seu ingresso e permanência na escola, para que alcancem maior nível de escolaridade, condições favorecedoras ao convívio social com autonomia, a uma vida econômica autônoma e vida social com maior engajamento político. Não temos todos os frutos já à mão. Não temos ainda como avaliar o impacto disso na vida de muitos sujeitos, porque alguns iniciaram nesse processo. As práticas das escolas são muito distintas: há aquelas que realmente se movimentam na direção de tentar atender as características, as peculiaridades da aprendizagem desses alunos; há outras em que esses alunos não têm provocado nenhuma reorientação da prática. A caminhada, no sentido de garantir a aprendizagem desses alunos é ainda muito longa.

Nesse contexto, é importante lembrar que não podemos tomar a instituição escolar como apartada de uma sociedade com características que marcam tempos distintos. Então, por mais que uma escola faça o movimento de repensar sua estrutura, suas ações pedagógicas, há um conjunto de problemas sociais que afetam sobremaneira a educação e influenciam a qualidade do ensino e a permanência dos alunos na escola. Há lutas a serem travadas no âmbito social mais amplo, para termos uma sociedade mais justa. A inclusão escolar é um objetivo educacional que está na dependência de mudanças sociais, econômicas, culturais...

4) Em 2006, há quase 10 anos, em publicação coordenada pela professora Dra. Valéria Amorim (USP), a senhora se posicionou sobre a formação de profissionais para trabalhar com o atendimento educacional de alunos com necessidades educacionais especiais no sistema regular de ensino.

Olh@res, Guarulhos, v. 3, n. 1, p. 219-236. Maio, 2015. 
Naquele momento, a senhora questionava o que se pretendia oferecer como conteúdo de ensino nos programas de formação e enfatizava a necessidade de sustentação teóricoprática para que mudanças pudessem ser almejadas: "Não há como mudar práticas de professores sem que os mesmos tenham consciência de suas razões e benefícios, tanto para os alunos quanto para a escola e o sistema de ensino quanto para seu desenvolvimento profissional". (p. 59) ${ }^{1}$

Como a senhora pensa hoje, decorridos 10 anos, sobre a atual situação da formação de professores para o trabalho com a população-alvo da educação especial? O que mudou?

No contexto de 2006, inicialmente, vale lembrar que ainda tínhamos as habilitações do curso de Pedagogia e, entre estas, as de educação especial.

1 MANTOAN, Maria Tereza Egler, PRIETO, Rosângela Gavioli, ARANTES, Valéria Amorim (Org). Inclusão Escolar : pontos e contrapontos. São Paulo : Summus, 2006. (pontos e contrapontos).
Aliás, as atuais Diretrizes da Pedagogia são exatamente deste ano. Então, temos mudanças nas orientações para a formação de professores e estas atingiram a área de educação especial. Até 2006, as habilitações em educação especial que existiam no Brasil estavam concentradas nas regiões Sudeste e Sul. Portanto, já não tínhamos cursos de formação de professores em educação especial em todo o território brasileiro. Com a extinção das habilitações, esta condição de ausência se generalizou. Não ter habilitações em educação especial não é o problema maior e, sim, o que fomos construindo nesses dez anos, para que a formação de professores especializados fosse garantida.

Falta-nos um projeto de formação de professores em educação especial construído pela articulação das instituições de educação superior - lócus da formação de professores - com o Estado, os movimentos sociais, as pessoas com deficiência. Temos um nicho aberto para as instituições privadas, que obviamente não tardam a apresentar alternativas, já que existe esta necessidade e procura.

Olh@res, Guarulhos, v. 3, n. 1, p. 219-236. Maio, 2015. 
$\mathrm{Na}$ formação inicial, há uma profusão de cursos mais generalistas, intitulados como de educação especial ou, predominantemente, de educação inclusiva. Neste último caso, da consulta a grade curricular desses cursos pode-se depreender que não fornecem subsídios nem para promover formação sobre gênero, diversidade sexual, raça e etnia e nem sobre educação especial, ou seja, tentam abarcar tudo aquilo que pode estar relacionado com diversidade e diferenças, ou ao campo da exclusão, seja da escola ou social, mas não oferecem condições de aprofundamento. Cursos de graduação específicos de educação especial ocorrem em apenas duas universidades brasileiras, nas Universidades Federais de Santa Maria e de São Carlos.

Quanto à formação continuada, podem ser apontadas algumas características que precisam ser revistas: é necessário incluir todos os profissionais nas ações de formação e não apenas os professores, como ocorre em muitos casos; as atividades carecem de regularidade e de continuidade, pois é comum em um sistema de ensino uma parte de seus professionais nunca terem participado de Olh@res, Guarulhos, v. 3, n. 1, p. 219-236. Maio, 2015. um curso e outros terem repetido formações com o mesmo teor ou nível de aprofundamento; os formadores de formadores por vezes desconhecem a estrutura, o funcionamento da rede de ensino para a qual está desenvolvendo os referenciais do curso, não contribuindo para uma reflexão que articule a teoria à prática.

No momento da publicação anteriormente referida, eu afirmava que não se podia fazer formação continuada, desprezando o conhecimento que os professores já tinham, partindo do pressuposto de que, para esta nova proposta, precisariam rever todo seu conhecimento e prática, pois isto nos levaria a desprezar sua história de saberes e fazeres.

Com essa afirmação, dizia que era preciso conhecê-los com muito mais clareza e maior aprofundamento, atentando para reunir informações sobre, por exemplo: quais são os referenciais teóricos que os professores adotam? Quais são os pressupostos que utilizam na sua prática pedagógica sobre ensino e aprendizagem? 
É a partir desse conhecimento que a formação continuada precisa ser planejada, provocando a aproximação de outros referenciais, para subsidiar práticas que respondam mais positivamente aos desafios atuais da escola. É tomar a experiência do professor como referencial de partida. Tanto a sua formação teórica como a sua experiência profissional são essenciais para que se possa discutir com eles: qual educação se pretende? Onde se quer chegar? Como se pode atingir os objetivos propostos? Se essas ideias não forem construídas em conjunto com os professores, é difícil pensarmos que os argumentos em favor da matrícula e permanência de alunos com deficiência na escola terão forças suficientes para convencê-los de que a inclusão escolar é um processo e, como tal, depende de aprimoramentos de nossas práticas.

5) Em nossos contatos com a escola pública, constatamos que ainda é comum os professores dizerem que "não se sentem preparados". Muitos são sim favoráveis à inclusão escolar de alunos com deficiência, mas não sabem Olh@res, Guarulhos, v. 3, n. 1, p. 219-236. Maio, 2015. como planejar práticas que favoreçam os processos de ensino aprendizagem com esses alunos. $E$ na formação continuada? Como podemos contribuir com o trabalho do professor que se pergunta: “- Por onde começo, nunca atuei com criança com deficiência?"

A primeira pergunta que me faço sobre este argumento é: o que esta afirmação "não estou preparado" nos informa? Pode apontar para uma resposta do tipo: "eu nunca tive acesso à formação sobre o tema"; "eu não tenho acúmulo de leituras e nunca tive uma prática". Pode nos informar também que para ensinar os outros alunos este profissional já se sente preparado, com conhecimento suficiente.

Todos esses caminhos explicativos são questionáveis. Não estou dizendo que são certos ou errados, mas são questionáveis. São facetas de uma informação que precisamos decodificar mais, porque entendemos pouco dessa fala dos professores "eu não estou preparado". "Estar preparado" pode assumir uma conotação de previsibilidade: de preparo para alguma coisa como antecipação a algo que já sei como acontecerá. Essa 
compreensão parece sustentar que o imprevisível só acontece quando há alunos com deficiência na turma. Mas, o imprevisível ou certo nível de imprevisibilidade acontece sempre. Quando trabalhamos com formação de professores, talvez tenhamos que entender um pouco mais de onde vem este discurso.

Contudo, não se pode desprezar na formação de professores perguntas como: "por onde começo? Nunca atuei com criança com deficiência”? Quando estou no papel de formadora de formadores, gosto de desenvolver o seguinte raciocínio com os participantes: que caminho eles fazem com os outros alunos? Porque a impressão é que às vezes se projeta nos alunos com deficiência a percepção de que eles são tão diferentes dos demais que é preciso inovar em tudo. Ou, ainda, que sem saber que deficiência o aluno tem, como ela se manifesta, quais são as características comportamentais ou físicas não se pode atuar pedagogicamente que depende muito mais da apreensão dos conhecimentos escolares que ele já possui, por exemplo, que estão no campo Olh@res, Guarulhos, v. 3, n. 1, p. 219-236. Maio, 2015. do que devemos e podemos saber sobre todos os alunos. E, na verdade, oferecemos um conjunto de conhecimentos que, muitas vezes, reforçam duas compreensões: uma de que eles são muito diferentes e a outra de que eles enquanto um grupo (de diferentes) são muitos semelhantes.

É interessante desenvolver o tema inclusão escolar de alunos com deficiência na formação continuada problematizando com os professores, o que fazem para conhecer todos os alunos e como usam essas informações para fazer seu planejamento anual e planos de aulas para buscar nessa discussão aquilo que poderia ser um bom começo, por exemplo: conhecer o aluno, incluindo o seu contexto familiar, social, econômico, sua história escolar anterior, o que ele gosta, o que ele já sabe fazer acerca do conteúdo escolar. Vejam que estou caminhando propositalmente na direção, não de ressaltar as limitações, mas de apreender repertório desse aluno, os seus conhecimentos, com o fito de agregar informações que subsidiem as intervenções pedagógicas. Se o professor não faz isso em relação à turma, talvez essa possa ser uma indicação interessante 
a ser incorporada em sua prática. Ao mesmo tempo, permite explorar as necessidades educacionais especiais desse aluno, o que de específico contribuiria para eliminar ou, ao menos, minimizar, as barreiras que impedem seu acesso ao conhecimento.

A ideia norteadora é não tomar as especificidades como justificativa para o discurso recorrente: "Tenho trinta alunos e mais um com deficiência". Essa afirmativa provoca a pensar que nos cursos de formação, se começarmos pelo específico - refiro-me como específico um conjunto de conhecimentos acerca de uma dada categoria de alunos, públicoalvo da educação especial - as contribuições dessas ações podem ser menores, pois acabam por reforçar apenas as especificidades do trabalho pedagógico com esses alunos e evidenciar o que os professores menos dominam, promovendo a sensação de impotência. As experiências que tomam como referência dado conjunto de conhecimentos que subsidiam o trabalho pedagógico em contextos heterogêneos, das diferenças têm surtido resultados mais animadores. Pode ser combatida a ideia Olh@res, Guarulhos, v. 3, n. 1, p. 219-236. Maio, 2015. de que somente professores especializados e outros profissionais detêm tal conhecimento. Os especialistas precisam do conhecimento do professor de classe comum sobre o aluno e viceversa.

6) No contexto dessa discussão, gostaríamos que falasse, mais especificamente, sobre a formação para o atendimento educacional especializado. Atualmente, com a extinção dos cursos de habilitação e a promoção de cursos de especialização, como ocorre e o que caracteriza esse processo: como se forma hoje o professor especialista para as salas de recursos/AEE, para quais atribuições é formado tendo em vista que, segundo a Política Nacional de Educação Especial na perspectiva da educação inclusiva (BRASIL，2007) ${ }^{2}$, as competências desse profissional devem ultrapassar o atendimento especializado e encampar

\footnotetext{
2 BRASIL, MEC/SEESP Política Nacional de Educação Especial na Perspectiva da Educação Inclusiva Documento elaborado pelo Grupo de Trabalho nomeado pela Portaria Ministerial $n^{\circ} 555$, de 5 de junho de 2007, prorrogada pela Portaria ${ }^{\circ} 948$, de 09 de outubro de 2007. http://peei.mec.gov.br/arquivos/politica_nacional_educacao_es pecial.pdf
} 


\section{o apoio à escola, no atendimento a essas crianças?}

Em documentos produzidos nos últimos anos, particularmente o que institui as Diretrizes operacionais para o atendimento educacional especializado na educação básica de 2009, há um aspecto importante sobre esse assunto: não se tratar apenas daquele conjunto de atribuições do professor especializado na sua ação direta com o aluno, ou seja, da sua atuação apenas na sala de recursos multifuncional.

Prevê também a realização de outras atribuições, como parte do atendimento educacional especializado. Na perspectiva de uma atuação complementar ou suplementar, transcende-se o atendimento direto ao aluno público-alvo da educação especial. Assim, o professor especializado e o professor de classe comum podem atuar colaborativamente, planejando a sua entrada na sala de aula, com compartilhamento de responsabilidades e de atividades e, desse modo, o conhecimento específico da área de educação especial se coloca a serviço daquela dinâmica pensada para turma Olh@res, Guarulhos, v. 3, n. 1, p. 219-236. Maio, 2015. desse professor do ensino comum, em que é constituída de alunos com diferentes formas e tempos de aprendizagem.

Um dos problemas nas propostas de formação continuada na área de educação especial, salvas exceções, consiste em disponibilizar cursos muito aligeirados, com baixa carga horária e, por vezes, desconsiderando as expectativas e necessidades de seus participantes. Vale lembrar que atuar como professor especializado atualmente pressupõe maior complexidade, porque este profissional precisa interagir com a escola como um todo. Portanto, é importante que reúna informações, que permitam compreender a história de funcionamento singular da escola, como e quais valores circulam na instituição, como são estabelecidas as relações entre os profissionais e as relações de poder, sobre seu projeto político pedagógico, as opções curriculares, a formação dos professores e outros profissionais da escola, entre outras. Precisam ser aceitos como parte daquela escola, daquele grupo, para que sua ação como professor especializado seja legitimada, respeitada e as trocas de conhecimentos fluam. Então, não consiste apenas em ter domínios específicos sobre 
educação especial e transmiti-los. É preciso também construir uma condição favorecedora do compartilhamento de conhecimentos sobre $\mathrm{o} / \mathrm{s}$ aluno/s. Os cursos de formação do professor de atendimento educacional especializado precisam chegar nessas dimensões.

7) Na sua opinião, como podemos pensar a formação inicial, no âmbito da graduação - Pedagogia e demais licenciaturas: é possível contribuir, via formação inicial, para a construção da base desse processo?

Vou abordar a resposta a essa pergunta sobre formação inicial na mesma direção de uma anterior, ou seja, se considero que avançamos nos últimos anos no Brasil. Eu vou afirmar: sim, mas não o suficiente, de modo a nos deixar em uma situação de conforto. Primeiro, fomos paulatinamente e de forma tímida implantando disciplina/s sobre educação especial nos cursos de Pedagogia (vou abordar essencialmente essa licenciatura neste momento). Por um lado, essa/s disciplina/s busca/m viabilizar aos estudantes a possibilidade de contato e Olh@res, Guarulhos, v. 3, n. 1, p. 219-236. Maio, 2015. apropriação de conhecimentos na área de educação especial (também não vou me ater a explorar qual o programa dessas disciplinas, porque apresentam muitas diferenças); por outro, esses conhecimentos sobre o alunado com deficiência, transtornos globais do desenvolvimento e altas habilidades não circulam nas demais disciplinas. Há de se caminhar no sentido da transversalidade desse tema, nas metodologias, na história da educação, na sociologia da educação, nas políticas públicas.

Há contribuições significativas no processo de inclusão escolar, para além da ampliação do número de matrículas desse alunado. Nunca, na nossa história, tivemos tantas pessoas envolvidas com esse tema, produzindo sobre educação especial, educação inclusiva etc. É óbvio que a produção merece uma avaliação e o fato das pessoas estarem envolvidas com essa temática, não necessariamente e de maneira linear, faz com que se avance, mas se cria uma condição favorecedora para essas pessoas ao menos discutirem esse tema, seja pelo incômodo à sua presença na escola, nos espaços sociais seja pela adesão à proposta inclusiva. A impressão que tenho, às vezes, é que 
fomos provocando mudanças, mas que nos encontramos em uma fase em que os avanços são menos perceptíveis. Há perguntas a serem respondidas e que sabemos pouco sobre elas, tais como: quantas pessoas com deficiência, transtornos globais do desenvolvimento e altas habilidades/superdotação continuam alijadas de seu direito à educação? Há quantos o direito ao atendimento educacional especializado está assegurado? O acesso ao conhecimento está ocorrendo?

\section{8) Ao longo das duas últimas décadas, a} ideia de inclusão escolar disseminou-se e também ganhou novos sentidos. No processo de sua apropriação, de usos do termo inclusão, são comuns as expressões: “inclusão efetiva, inclusão verdadeira", assim como seu uso para categorização de educandos, escolas, professores: aluno de inclusão, escola de inclusão etc. Em sua opinião, há alguma contradição entre o princípio de educação inclusiva e as novas categorizações, do processo e dos atores envolvidos, que ganham forma nos usos Olh@res, Guarulhos, v. 3, n. 1, p. 219-236. Maio, 2015.

\section{do termo inclusão?}

Considero que já estamos adjetivando a educação com a sua associação ao termo inclusiva, o que pode ter dois sentidos. Por um lado, denunciar a exclusão e, por outro, indicar que é preciso mudar a educação, para não continuar reproduzindo os mecanismos de exclusão já conhecidos, ou até não tão conhecidos, mas existentes nas escolas. Mas, esses recursos e outros - inclusão efetiva... verdadeira... - somente revelam que precisamos de mais investimentos político e econômico, ao menos, para atingir qualidade de ensino para todos.

Há descompassos entre o que é preconizado nas orientações e legislação e aquilo que se compreende, interpreta sobre estas, aquilo que se traduz destas em ações do Estado. Há distorções na implantação da política de inclusão escolar em escolas, quando compreendida como a mera matrícula desses alunos na classe comum. Nem no campo teórico nem na legislação consta esse reducionismo, embora precise ficar claro que não há processo de inclusão escolar sem matrícula. Não existe ação no campo 
da escola, do sistema de ensino que se dê, sem que esses alunos estejam na escola. Aliás, por eles, historicamente, estarem fora da escola, essa instituição foi sendo organizada, desconsiderando os alunos público-alvo da educação especial, e, se continuamos esperando que a escola mude para que um dia eles entrem para escola, apenas repetiremos essa mesma história. Como organizar ações na perspectiva da inclusão sem que o aluno esteja na escola?

Vale ponderar que as práticas atuais são muito distintas; há escolas em que a compreensão de inclusão escolar se encerra na ideia da matrícula; há aquelas com movimentos interessantes, tentando se repensar enquanto uma instituição com responsabilidade de garantir conhecimento e aprendizagem para os seus alunos, em toda a sua diversidade. Nesse contexto, as experiências são múltiplas.

De qualquer maneira, gostaria de também deixar uma provocação: é a escola a grande responsável pela inclusão? Qual é o grau de autonomia que conferimos à escola ou qual grau de autonomia pode Olh@res, Guarulhos, v. 3, n. 1, p. 219-236. Maio, 2015. esta instituição assumir diante dessa política, até porque, por exemplo, há alunos público-alvo da educação especial que requerem ações articuladas entre saúde, educação, assistência social e outras áreas, de políticas públicas de cunho social. Certamente, as escolas que têm conseguido pelo menos logicamente falo do meu conhecimento sobre escolas - dar respostas interessantes na direção de garantir a aprendizagem dos alunos são as que têm projetos mais ousados, com experiência de gestão mais democratizantes que, saindo do âmbito da formalidade da participação, realmente buscam envolver todos os seus funcionários técnico-administrativos, professores, estudantes, familiares nos debates, decisões, ações, não apenas como expectadores críticos.

Há elementos anunciadores do que tem dado mais certo na melhoria da qualidade da educação e na implantação e consolidação de processos inclusivos: a gestão democrática, o apoio da equipe gestora e ações dos profissionais da educação especial na escola. Por exemplo, numa das últimas pesquisas que coordenei fui conhecer o trabalho de professores de educação especial, 
indicados por terem sua prática reconhecida como exitosa, em quatro escolas municipais de duas diferentes regiões de São Paulo, duas da educação infantil e duas de ensino fundamental. Nas visitas às escolas, explorei junto aos professores especializados regentes de salas de recursos a organização e funcionamento do atendimento educacional especializado que realizavam, seus projetos, seu planejamento, como compreendia seu papel na escola, entre outros temas. Em seus relatos avaliaram como fundamental o apoio da equipe gestora, para o desenvolvimento de várias ações necessárias para o atendimento das necessidades dos alunos com deficiência e transtornos globais do desenvolvimento, em que lhe era garantida participação nas reuniões coletivas, para compartilharem conhecimentos e orientarem professores da classe comum. Também por ação da escola, quase todas as salas de recursos estavam provisionadas com variados equipamentos e materiais necessários ao desenvolvimento do atendimento educacional especializado. Valorizavam e incentivavam a participação das famílias ou responsáveis pelos alunos na elaboração das propostas de atendimento dos alunos. Tinham ações junto com os professores das classes comuns e declaravam sentir seu trabalho valorizado pelos colegas.

9) A leitura de seus trabalhos nos permite entender que a senhora atribui um importante papel à universidade nos processos que concorrem para a construção de políticas e práticas de educação especial numa perspectiva inclusiva. Poderia concluir falando um pouco sobre o tema? Sobre como, de sua perspectiva, a universidade através de ações de pesquisa, docência e extensão participa desse processo? Como, em sua experiência como pesquisadora, isso pode se concretizar?

Uma das contribuições, além do ensino e da extensão, é avançarmos nas pesquisas na área de educação especial. Tenho feito pesquisas com a participação direta de profissionais de redes municipais, o que acaba se constituindo em uma relação de aprendizagem mútua, de trocas. É fato que estar na universidade pode gerar certo

Olh@res, Guarulhos, v. 3, n. 1, p. 219-236. Maio, 2015. 
distanciamento da rede, se você não tomar cuidado e não estreitar laços, tanto na pesquisa como nas outras ações da universidade com os sistemas educacionais.

A universidade é um espaço privilegiado para agregar profissionais que atuam em educação e nesta desenvolvem ações de inclusão de alunos com deficiência, transtornos globais do desenvolvimento e altas habilidades/superdotação. As ações de extensão - grupos de estudos, cursos... - favorecem a aproximação destes com a universidade e a troca de conhecimentos.

10) Nossa aproximação da escola, em programas de estágio e extensão, nos dá acesso a distintos relatos do processo de inclusão escolar: alguns apontam para o engajamento bastante positivo de prefeituras, educadores e famílias de forma que concorre para o desenvolvimento da criança; outros relatos, a maioria, evidenciam o confronto de posições dos autores envolvidos frente ao tema e as práticas de inclusão escolar denotam a grande distância entre princípios e vida escolar, sendo o direito fundamental à Olh@res, Guarulhos, v. 3, n. 1, p. 219-236. Maio, 2015. educação nem sempre garantido. Dessa perspectiva, ainda considerando sua trajetória e vasta experiência, o que aponta como lacunar, como falha que nesse processo distancia o princípio dos modos de sua efetivação? O quê, em sua opinião, ainda precisa ser feito, superado?

É certo que precisamos de muitas intervenções e também não podemos dizer que não avançamos em nada. Quem trabalhou nas décadas de 1970 a 1990 na educação especial entende como era diferente a perspectiva de trabalho. De fato, considerávamos os alunos com deficiência muito mais nas suas limitações do que nas suas possibilidades. Hoje buscamos construir outra perspectiva, que consiste em ressaltar suas potencialidades, aquilo que o aluno pode fazer, em prever intervenções na escola para lhes oferecer condições de aprendizagem. Temos tentado substituir práticas desprovidas de significado por aquelas que provoquem $\mathrm{o}$ desenvolvimento de sua autonomia e independência.

Aprovamos há quase um ano o Plano Nacional de Educação e neste constam 
muitas metas e estratégias para orientar a política na próxima década. Trata-se de efetivar os direitos, criando condições de sua implantação. De imediato estamos às voltas com a elaboração ou revisão dos planos estaduais e municipais de educação e é dever de todos contribuir para o aprimoramento das metas e estratégias, gerais e específicas, para garantir o atendimento escolar com qualidade de pessoas com deficiência, transtornos globais do desenvolvimento e altas habilidades/superdotação, em todos os níveis e modalidades de ensino.

Olh@res, Guarulhos, v. 3, n. 1, p. 219-236. Maio, 2015. 